\title{
Clonal analysis of chimaeric mouse ovaries using DNA in situ hybridization
}

\author{
N. I. Boland and R. G. Gosden \\ Department of Physiology, University of Edinburgh Medical School, Teviot Place, \\ Edinburgh EH8 9AG, UK
}

\begin{abstract}
Analysis of chimaeric mouse ovaries using DNA in situ hybridization was undertaken to (i) investigate the morphogenesis of follicular cell clonal expansion, (ii) evaluate whether the different cell populations within the ovary are derived from the same or unrelated progenitor cells and (iii) estimate the number of progenitor cells giving rise to the different types of ovarian cell. Chimaeras were produced by aggregation of eight-cell morulae from normal mice and those transgenic for the $\beta$-globin gene. Chimaeric blastocysts were transferred to pseudopregnant hosts and the ovaries of resultant adult offspring were prepared for in situ hybridization using a digoxigenin-labelled cDNA probe to the $\beta$-globin gene. Results showed that follicles are constructed by the non-random, radial proliferation of granulosa cell clones, which form long, thin, unbranched columns across the follicle wall. Qualitative and quantitative studies revealed that both peripheral and central granulosa cells are derived from the same progenitor cells. Phenotypic differences may therefore be due to positional cues within the follicle rather than being cell lineage dependent. It is suggested that granulosa cells and germinal epithelium may be partly derived from the same progenitor cells and that theca externa is probably derived from interstitial tissue. However, results from this study did not support the contention that theca interna and theca externa-interstitial tissue have the same origin, and it is suggested that the former cell type may exist in an undifferentiated state from early stages of follicle development. Furthermore, granulosa and germinal epithelium appear to be derived from different progenitor cells from either theca interna or theca externa-interstitial cells. Evidently, all types of ovarian cell, including the somatic cells of individual follicles, are derived from more than one progenitor cell.
\end{abstract}

\section{Introduction}

Follicles are the fundamental developmental units of ovaries and consist of three types of cell. A single, central oocyte is enclosed by enveloping layer(s) of epithelial-like cells, the membrana granulosa, which rest on a basement membrane. The boundary of the follicle is defined by theca cells, which consist of secretory and fibroblast-like cells. These phenotypically distinctive types of cell are considered to have different origins. Although germ cells are from extraembryonic tissue (Ginsburg et al., 1990), somatic cells emerge from the urogenital ridge, although their precise origins are still unknown. Granulosa cells are probably derived from the intra-ovarian rete in mice, perhaps with contributions from the ovarian surface epithelium (Byskov, 1986). However, theca cells are considered to originate among the mesenchymal cells of the ovarian stroma.

During the course of development, follicle cells undergo a fixed programme of growth and differentiation which brings the primordial follicle, consisting of a small oocyte with only a single layer of pregranulosa cells, to a Graafian stage with a mature oocyte, more than 50000 granulosa cells and layers of differentiated theca cells. Towards the end of the growth span when about 3000 granulosa cells have accumulated, a cleavage forms within the granulosa epithelium to produce a fluid-filled cavity, the antrum. At this stage, two distinct types of granulosa cell differentiate: the central cumulus cells which surround the oocyte and mural cells located more peripherally.

Knowledge of cell lineages and the character of growth patterns of ovarian follicles is still rudimentary. Telfer et al. (1988), using mice heterozygous for the X-linked glycolytic alloenzyme, PGK-1, showed that granulosa cells of Graafian follicles derive from approximately five precursors and that cumulus and mural cells have a common origin. Since the clones could not be visualized, however, the extent of cell mixing at the various stages was unclear. Nor could they deduce whether successive layers of cells form segmentally or by radial growth. Even less is known about the character of theca cells and their origins within the stromal cell population.

The present study was designed to address these questions with the aim of clarifying cellular lineages and patterns of growth from primordial to Graafian stages in the mouse ovary. Chimaeric mice in which one of the partner embryos was 
derived from a transgenic mouse were used to measure and trace clonal expansion of follicle cells using a DNA in situ hybridization marker.

\section{Materials and Methods}

\section{Chimaeras}

Animals. Mice were housed in a temperature- and lightcontrolled room with a $14 \mathrm{~h}$ light:10 $\mathrm{h}$ dark photoperiod in accordance with the principles outlined in the National Institutes of Health $(\mathrm{NIH})$ guide for the care and use of laboratory animals.

Production of embryos. Five-week-old female BALB/c and $\mathrm{F}_{1}$ $(\mathrm{C} 57 \mathrm{BL} / 6 \times \mathrm{CBA} / \mathrm{Ca})$ mice were superstimulated by i.p. injection with 5 iu and 2 iu of pregnant mares' serum gonadotrophin (PMSG) (Organon Laboratories, Surrey), respectively. Superovulation was induced $42 \mathrm{~h}$ later by i.p. injection of 5 iu hCG (Chorulon: Intervet Laboratories, Cambridge) and the mice were then caged in pairs with one male for mating overnight.

Eight-cell embryos were produced from the matings of female $\mathrm{BALB} / \mathrm{c} \times$ male $\mathrm{BALB} / \mathrm{c}$ and female $\mathrm{F}_{1} \times$ male transgenic mice homozygous for the $\beta$-globin transgene. The homozygous transgenic mice were derived from the original transgenic strain 83 (from Cecilia Lo), and had a mixed genetic background with contributions from inbred strains CBA, C57BL/6 and SIL. The transgene comprised approximately 1000 tandemly repeated copies of a mouse $\beta$-globin plasmid inserted near the telomere of chromosome 3 (Lo, 1986).

Harvesting of embryos. Eight-cell embryos from the two sets of matings were harvested $72 \mathrm{~h}$ after hCG injection (Mintz, 1971) and removed from their zonae pellucidae using acid Tyrode's medium (Nicholson et al., 1975).

Construction of chimaeras. Two embryos, one BALB/C and one transgenic, were placed in each well of a non-tissue culture treated 96-V-well microtitre plate (Bibby Sterilin, Staffordshire) in $20 \mu \mathrm{l}$ droplets of $\alpha$-minimal essential medium (MEM; Gibco-BRL, Irvine) under mineral oil (Sigma, London; density: $0.84 \mathrm{~g} \mathrm{ml}^{-1}$ ). Medium was supplemented with $2 \mathrm{mmol}$ pyruvate $\mathrm{l}^{-1}, 2 \mathrm{mmol}$ glutamine $\mathrm{l}^{-1}, 10 \mu \mathrm{g}$ bovine insulin $\mathrm{ml}^{-1}$, $10 \mathrm{ng}$ epidermal growth factor (EGF) $\mathrm{ml}^{-1}$ and $3 \mathrm{mg}$ BSA fraction $\mathrm{V} \mathrm{ml}^{-1}$ (all Sigma) and the embryos were allowed to aggregate at $37^{\circ} \mathrm{C}$ by rolling down the walls of the $V$-well (Fig. 1). The aggregation and culture of chimaeric embryos in the $\mathrm{V}$-wells of a microtitre plate is a modification of the standard techniques for making mouse chimaeras and overcomes the need for manually aggregating the embryos. Manual aggregation takes a considerable time, during which embryos are exposed to changes in temperature and the possible damaging effects of squeezing with forceps or repeated pipetting. If the embryos are allowed to roll together by gravity down the walls of the $\mathrm{V}$-wells, a $100 \%$ aggregation rate is obtained compared with $80 \%$ when forceps are used.

The resultant chimaeric morulae were then incubated overnight at $37^{\circ} \mathrm{C}$ in a humidified atmosphere of $5 \% \mathrm{CO}_{2}$ in air to facilitate blastocyst development. A proportion of the BALB/c

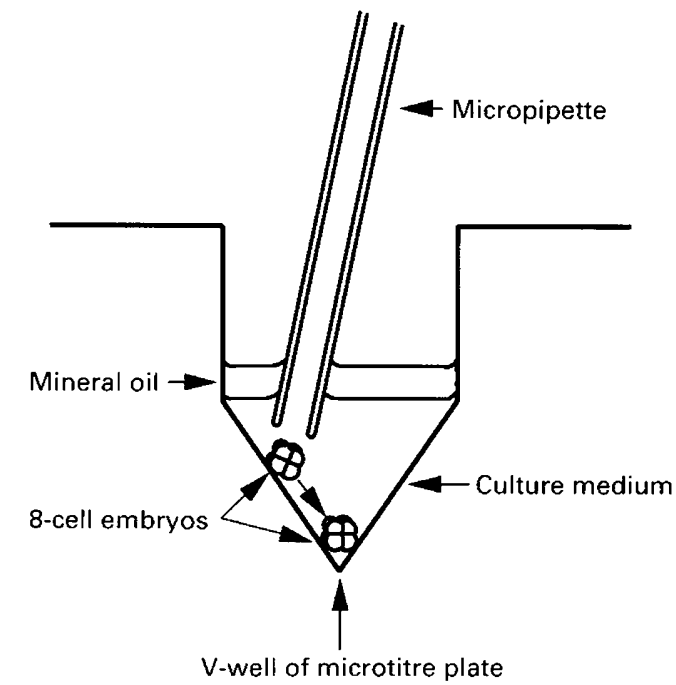

Fig. 1. Diagram illustrating the technique developed for mouse embryo aggregation.

and transgenic embryos were cultured independently in the $\mathrm{V}$-wells of the microtitre plate to provide a number of helper embryos' which would aid implantation of the chimaeras in the host mother when there were few chimaeras, and also to provide positive and negative control animals for the in situ analysis.

Embryo transfer. Pseudopregnant female $\mathrm{C}_{3} \mathrm{H}$ mice were used as hosts to the resultant chimaeric and helper embryos (Mintz, 1971). Chimaeric offspring were identified by their brown and white patched coat colour.

\section{DNA in situ hybridization}

Digoxigenin labelling of DNA probes. The mouse $\beta$-globin probe, $\mathrm{pM} \beta \delta 2$, was labelled with digoxigenin-dUTP by random primed labelling using the DNA labelling and nonradioactive detection kit (Boehringer Mannheim, Lewes) according to the manufacturer's instructions. The digoxigenin labelling efficiency of the cDNA probe was checked by dot blot hybridization (Keighren and West, 1993), and the probe was not used unless a clear signal was produced at $0.5 \mathrm{pg}$.

Preparation of tissue. At eight weeks of age, six female chimaeras, three BALB/c mice (negative control) and three $\mathrm{F}_{1} /$ transgenic mice (positive control) were anaesthetized with tribromoethanol $\left(0.63 \mathrm{~g} \mathrm{~kg}^{-1}\right.$ body weight i.p.) and exsanguinated by perfusion with heparinized saline (1000 $\mathrm{U} \mathrm{I}^{-1}$ ) followed by $3: 1(\mathrm{v}: \mathrm{v})$ ethanol:acetic acid via cannulation of the aorta. After $30 \mathrm{~min}$, ovaries were dissected out and transferred to fresh $4 \%$ paraformaldehyde for fixation overnight. The following day, the tissue was dehydrated through a graded series of ethanol concentrations and transferred from absolute ethanol to toluene for clearing. The tissue was then embedded in paraffin wax and sectioned on a microtome at $6 \mu \mathrm{m}$. Sections were transferred to glass slides $(\mathrm{BDH}$, Merck Limited, Leicestershire) coated with 3-aminopropyltriethoxysilane (TESPA: Sigma) in preparation for in situ hybridization. 
In situ hybridization. In situ hybridization with a digoxigenin-labelled cDNA $\beta$-globin probe was carried out according to the method described by Keighren and West (1993), using alkaline phosphatase as the end point. After hybridization, slides were lightly stained with haematoxylin and eosin before being mounted with glycerol jelly $(\mathrm{BDH})$.

\section{Analysis of chimaeric and control ovaries}

Genetic sex determination of chimaeras. The $Y$ chromosomespecific probe, pY353/B (kindly provided by Colin Bishop, Institut Pasteur, Paris) was used to determine the genetic sex of the chimaeric offspring by in situ hybridization (Keighren and West, 1993). One slide from each chimaeric and control mouse was analysed using the $\mathrm{Y}$-probe, and each tissue section examined for the presence of positive hybridization signals.

Qualitative analysis of clonal patterning. Sections of ovaries from chimaeras were examined using a Leitz Diaplan microscope to study the pattern of clonal growth in follicles at all stages of development as well as in the corpus luteum, interstitial tissue and surface epithelium. Unbalanced chimaeras with a low percentage contribution of $\mathrm{F}_{1} /$ transgenic genotype were the best candidates in which to study clonal patterning, as the shape of individual patches of labelled cells could be clearly seen against a large background of unlabelled cells.

Quantitative lineage analysis. Oil immersion optics $(\times 1000)$ were used to determine the number of labelled cells (hybridization signals) in the granulosa and theca layers of 50 preantral and 50 antral follicles from each 'balanced' chimaeric mouse (as defined by coat colour; approximately 50:50, BALB/c: $\mathrm{F}_{1} /$ transgenic).

Only those follicles sectioned approximately equatorially, as indicated by the germinal vesicle nucleus, were included in the analysis. The proportion of labelled granulosa and theca cells in each preantral follicle was calculated by counting the number of labelled cells in each follicle compartment and dividing this by the total number of cells. For antral follicles, the proportion of labelled cells in 20 high power fields of view $(\times 1000)$ per follicle was determined for the theca and granulosa layers: ten from the mural granulosa layer and ten from the antral granulosa layer to study the clonal origin of these two granulosa subpopulations, and similarly for theca externa and theca interna. Both preantral and antral data were analysed separately to investigate the possibility of differential clonal growth between the two distinct phases of follicle development. In addition, the number of labelled cells in 50 samples of interstitial tissue and surface epithelium was also determined for each balanced chimaera (one sample for interstitial tissue was taken in close proximity to each follicle sampled, and samples for surface epithelium were taken at random). Positive and negative control ovaries were scored in the same manner by determining the percentage of labelled cells in 50 random samples per slide.

Chimaeric data were plotted as the proportion of samples for each cell type that showed a labelling percentage between 0 and $100 \%$. Chi-square analysis was used to determine the clonal relationship between the different cell types by comparing their frequency distributions. The number of clones of cells giving rise to each tissue was then estimated using binomial statistics to determine the variance between samples (Nesbitt, 1971; Stone, 1984). If a particular tissue is derived from only one progenitor cell, then all the cells of that tissue will be either totally labelled or unlabelled. However, if the tissue is derived from a large number of progenitor cells then there is a high probability that tissue will contain equal proportions of both labelled and unlabelled cells with a small variance. Intermediate situations betwen these two extremes may be analysed by using binomial statistics to estimate the variance in proportional labelling between follicles. Each chimaera was analysed separately.

$$
n=p(1-p) / \sigma^{2}
$$

where: $p=$ the mean proportion of labelled cells; $I-p=$ the mean proportion of unlabelled cells; $\sigma^{2}=$ the sample variance; and $n=$ the number of clonal precursors.

The principle of using variance between samples to estimate number of progenitor cells has previously been used in the analysis of $\mathrm{X}$-inactivation mosaics, which are subject to less variation in terms of cell selection than are chimaeras. Although data from only the 'balanced chimaeras' (equivalent in genetic composition to $\mathrm{X}$-inactivation mosaics) were used in this analysis, the number of clonal progenitors calculated for a given tissue using this statistical approach should only be used as a rough guide, and does not bear the weight of numerical precision. In the context of this investigation, the binomial equation was used to determine whether different types of cell within the same chimaera had a common origin, by comparing the number of calculated progenitor cells (or descendent clones).

Quantitative analysis of clonal shape. Quantitative analysis of digoxigenin-labelled granulosa cells was undertaken to discover whether these clones exhibited a random clonal pattern within the membrana granulosa, or whether the clones were linear in one particular direction suggesting a non-random pattern of growth. Five antral follicles exhibiting a clearly defined clonal pattern were selected from each chimaera. Only those follicles with a proportion of labelled cells $(p)$ close to 0.5 were used in the analysis. Five serial sections through the oocyte of each follicle were photographed and then analysed by scoring the number of labelled cells along five lines drawn at random from the basement membrane to the oocyte (radial). In addition, five concentric rings were drawn within the membrana granulosa at random around the oocyte (circumferential), and labelled cells along these lines were scored accordingly. The proportion of labelled cells $(p)$ along the radial and circumferential lines for each follicle was then calculated and the results compared using Student's t test. If the pattern is stripes from oocyte to basement membrane then the radial value for $p$ should be very variable, often close to 0 or 1 , and the circumferential value of $p$ should be less variable and close to the overall proportion of cells in the follicle. If the pattern is rings of clones around the follicle then the converse applies. If no significant difference exists between the radial and circumferential values of $p$, then the clonal patterning is random. 


\section{Results}

\section{Chimaeras}

Six female $X X \leftrightarrow X X$ chimaeras were produced from the embryo transfers and selection between the component strains was not apparent, as four of the six females were 'balanced' and the remaining two were 'imbalanced' in both directions.

\section{Analysis of control slides}

Positive and negative control slides were analysed after in situ hybridization to confirm that each experiment had achieved $\geqslant 99 \%$ labelling efficiency, and that no detectable background labelling had occurred. The overall mean percentage labelling for positive and negative controls was $99.7 \pm 0.05 \%$ and $0 \%$, respectively. Each cell in the positive controls had a single label, which is to be expected from diploid cells in hemizygous individuals.

\section{Morphogenesis of ovarian follicles}

Six chimaeras were used to study the clonal patterning in follicles at all stages of development. Analysis of the preantral granulosa layer revealed that the distribution of labelled and unlabelled cells was not random: labelled cells were clustered together to form patches or clones which stretched across the full width of the follicle wall (Fig. 2a). For all preantral follicles studied, the labelled cells formed columns from basement membrane to oocyte, and there was no apparent lateral growth, or branching, between patches within each follicle. This latter observation was confirmed by tracing through serial sections from 20 follicles chosen at random. During the later stages of antral development, the same non-random pattern of labelling was seen (Fig. 2b) and patches of cells formed long, thin, unbranched columns from the basement membrane to the antral cavity (Fig. 2c). This pattern was confirmed quantitatively by the observation that radial and circumferential proportions of labelled cells were significantly different $(P \leqslant 0.001$; $n=750)$ for all follicles studied. The proportional labelling ( $p$ ) for radial clonal growth was very variable, either close to 0 or $1(p=0.08 \pm 0.01$ and $p=0.92 \pm 0.03 ; P \leqslant 0.001 ; n=381$ and $n=369$, respectively). However, the value of $p$ for circumferential clonal growth was close to the overall proportion of labelled cells in the follicles studied (circumferential $p=0.47 \pm 0.02$ and overall $p=0.49 \pm 0.03 ; P \geqslant 0.05$ ). This radial pattern of clonal growth demonstrates that there is no difference in the pattern of labelling associated with the peripheral and central granulosa cells. The spatial arrangement of patches within the cumulus region of large antral follicles was also non-random; however, the patches were rather more oval than columnar in this region (Fig. 2d). For most follicles studied, a large patch of either labelled or unlabelled cells was seen at the base of the cumulus stalk.

The pattern of labelled cells in the theca interna was typically non-random, and the patches formed were found to be fairly large when labelled cells were traced through serial sections of follicles. There was evidence of extensive lateral coherent growth of these clones around approximately one quarter of the follicle wall. Surface epithelium, analysed in a similar manner, also exhibited the same non-random pattern of labelling. However, theca externa and interstitial tissue appeared to have identical random patterns of labelled and unlabelled cells when cells were followed through serial sections. In contrast to the granulosa layers, a more-or-less random pattern of labelling was also observed in the corpus luteum (Fig. 2e).

A striking difference was often noted in the frequency of labelling between the layers of the granulosa and theca interna within the same follicle (Fig. 2 f) and, indeed, between these two types of cell and the theca externa-interstitial cells. This discrepancy in labelling frequency between all three types of cell (theca externa and interstitial tissue are now classified together as there was no apparent difference in labelling frequency or clonal patterning) was observed in most follicles studied. In addition, the cells immediately surrounding the early preantral follicles (putative theca interna) had a noticeably different labelling frequency compared with the interstitial tissue beyond, and this difference was apparent throughout follicle development.

\section{Clonal history of ovarian cell types}

The 'balanced' chimaeras were analysed to determine the clonal relationship between granulosa cells, theca interna, theca externa-interstitial cells and surface epithelium, and to estimate the number of progenitor cells giving rise to each type of cell.

There was no significant difference between the frequency distributions for peripheral and central granulosa cells $(P>0.5)$, or between the number of calculated progenitor cells $(P>0.5)$, indicating that these two subpopulations of granulosa cells probably derive from the same precursor pool (Fig. 3). Frequency distributions for preantral granulosa and granulosa cells from antral follicles (both peripheral and central) were not significantly different $(P>0.5)$, and again, there was no statistical difference between the number of progenitors $(P>0.5)$. It is therefore unlikely that differential clonal proliferation occurs between the phases of preantral and antral follicle development, or that immigration of cells occurs across the basement membrane. A similar relationship was found between the frequency distributions $(P>0.5)$ and number of progenitors $(P>0.5)$ for theca interna and putative theca interna (undifferentiated cells adjacent to the developing follicle) from antral and preantral follicles, respectively (Fig. 4).

The frequency distributions of percentage of labelled granulosa (pooled data), theca interna (pooled data) and theca externa-interstitial cells are shown (Fig. 5). The distributions and numbers of progenitors for all three types of cell were significantly different $(P<0.05)$. This finding suggests that these types of cell are not closely related to one another clonally, and may arise from different, or only partially related, precursor pools.

There was no significant difference between the frequency distributions for surface epithelium and granulosa cells $(P>0.5)$; however, the number of calculated precursors for the two types of cell was significantly different $(P<0.001)$ (Fig. 6). This finding suggests that these two types of cell may have progenitor cells in common. Comparisons between the frequency distributions for surface epithelium and theca interna, and surface epithelium and theca externa-interstitial tissue 

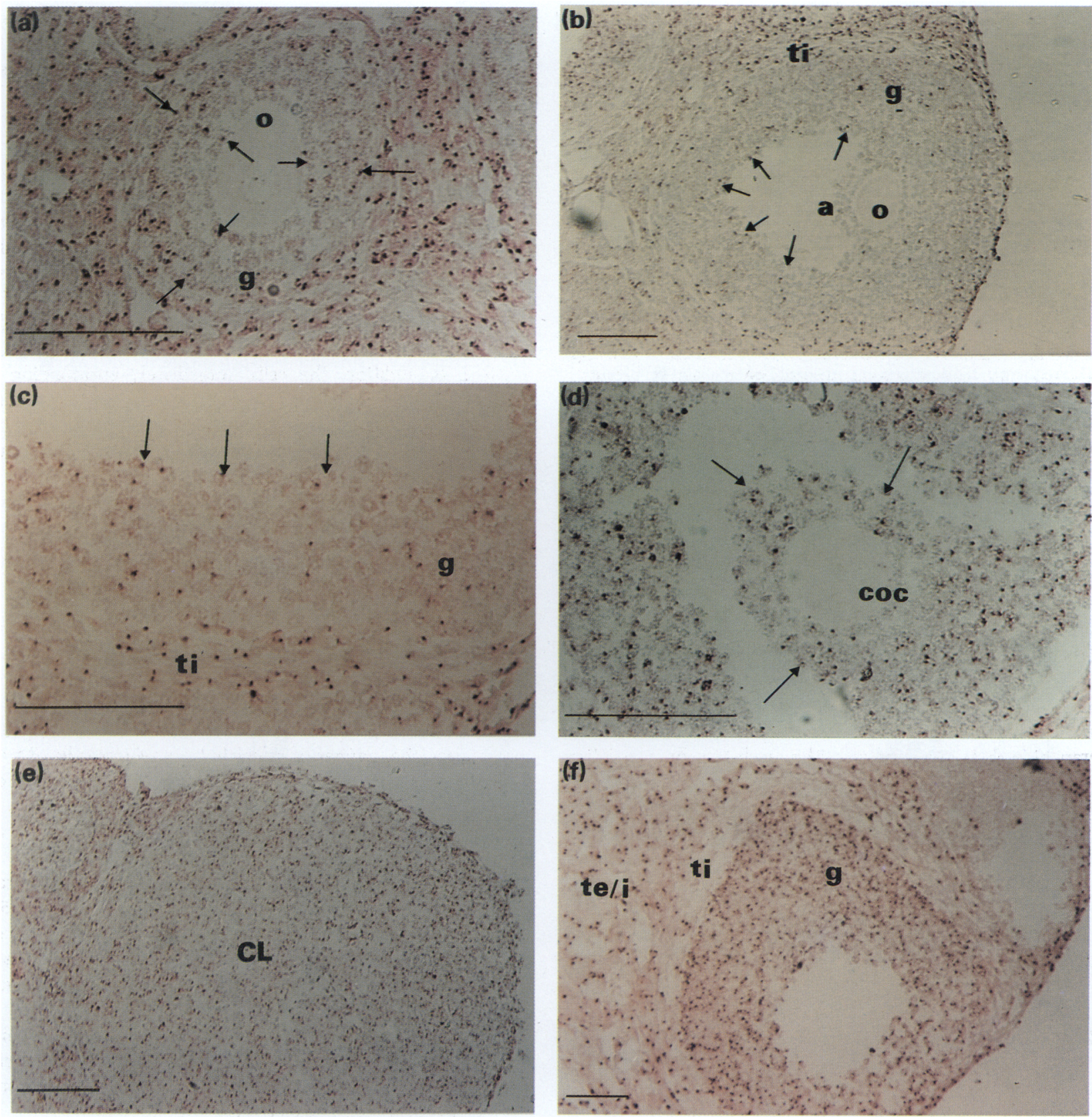

Fig. 2. (a) Preantral chimaeric mouse follicle showing a non-random pattern of cell labelling (arrows). (b) Mid-antral chimaeric mouse follicle showing long columns (arrows) of labelled cells stretching right across the granulosa layer. (c) Wall of mid-antral chimaeric mouse follicle (b) showing the columns (arrows) of labelled cells in more detail. (d) Cumulus-oocyte complex from a large antral chimaeric mouse follicle showing a non-random labelling pattern of oval patches (arrows). (e) Corpus luteum from a chimaeric mouse showing a random pattern of labelling in contrast to the granulosa layers of developing follicles in (a) to (d). (f) Mid-antral chimaeric mouse follicle illustrating the difference in the labelling frequencies between granulosa cells, theca interna and theca externa-interstitial tissue. a: antrum; $\mathrm{CL}$ : corpus luteum; COC: cumulus-oocyte complex; g: granulosa cells; $\mathrm{O}$ : oocyte; te/i: theca externa-interstitial tissue; ti: theca interna. Bars represent $100 \mu \mathrm{m}$.

indicated that these types of cell were probably not clonally related to one another $(P<0.05$ and $P<0.05$, respectively).

\section{Discussion}

The study reported here demonstrated that granulosa and theca cells have different origins and undergo distinctive patterns of clonal expansion. The absence of much cell mixing and the small number of clones involved provided the opportunity to explore developmental patterns in detail using a discrete transgene marker.

The granulosa cell layers appeared to grow segmentally (like an orange) rather than radially (like an onion). Long, thin, unbranching columns of labelled cells were observed stretching 


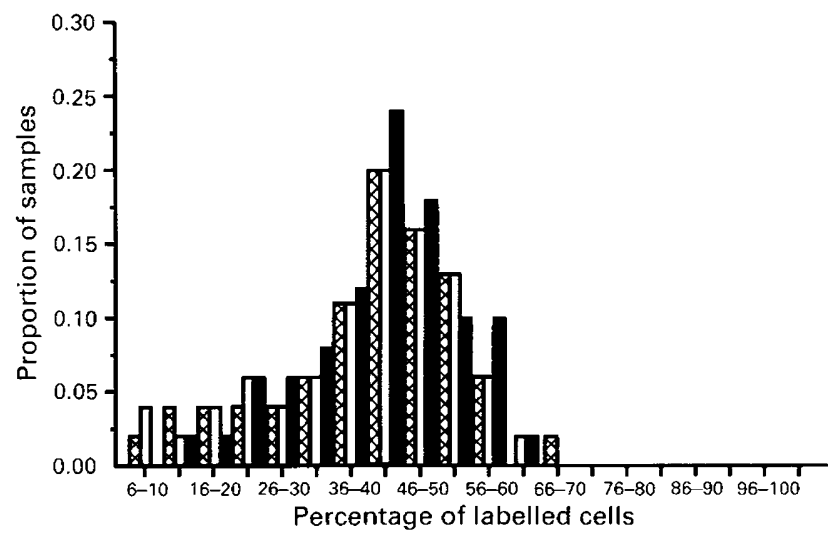

Fig. 3. Frequency distributions of percentage of labelled ( $\boldsymbol{\square}$ ) preantral granulosa cells and $(\otimes)$ peripheral and $(\square)$ central granulosa cells from antral chimaeric mouse follicles. There were five progenitor cells for the peripheral granulosa cells, central granulosa cells and preantral granulosa cells. The standard errors of the differences between chimaeras was $4.7 \pm 0.15,4.6 \pm 0.17$ and $4.8 \pm 0.2$, respectively.

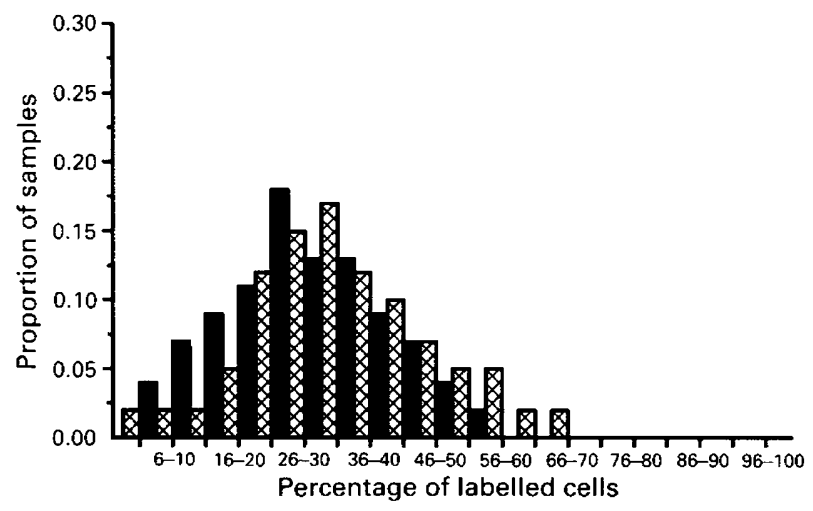

Fig. 4. Frequency distributions of percentage of labelled cells in $(凶)$ the theca interna of antral follicles and $(\boldsymbol{a})$ putative theca interna of preantral chimaeric mouse follicles. There were two progenitor cells for all populations of granulosa cell; the standard errors of the differences between chimaeras was $2.4 \pm 0.1$ for antral theca interna and $2.2 \pm 0.1$ for putative preantral theca.

from the basement membrane to either the oocyte or antrum. This finding implies little cell mixing and that the epithelium consists of a number of coherent clones. In addition, the absence of branching from the labelled columns of granulosa cells observed through serial sections of follicles suggests that clonal growth is not random. In the cumulus oophorus the clones appeared to be more rounded than were those in the follicle wall, suggesting some relaxation of restraint on lateral movement. In contrast to other areas of the wall, a large patch of uniformly labelled or unlabelled cells was frequently observed at the base of the stalk supporting the cumulus oophorus. This finding is consistent with the earlier finding that rapid proliferation continues in this zone after mitosis has ceased in other parts of the follicle periphery (Gosden et al., 1983). The numbers of clonal progenitors estimated from the proportions of labelled:unlabelled granulosa cells using

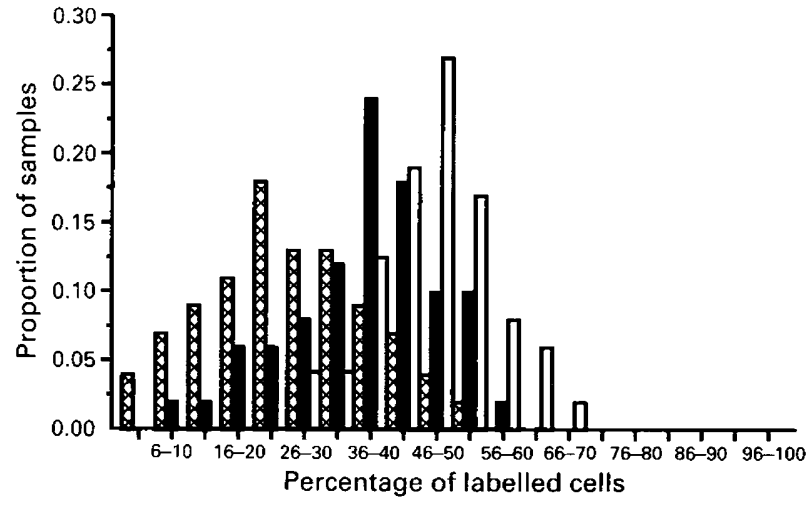

Fig. 5. Frequency distributions of percentage of labelled ( $\mathbf{a}$ ) granulosa cells, $(\mathbb{X})$ theca interna and $(\square)$ theca externa-interstitial cells from chimaeric mouse follicles. The numbers of progenitor cells for each distribution were theca externa-interstitial cells (8), granulosa cells (5) and theca interna (2) and the standard errors of the differences between chimaeras were $7.6 \pm 0.1,4.6 \pm 0.2$ and $2.3 \pm 0.1$, respectively.

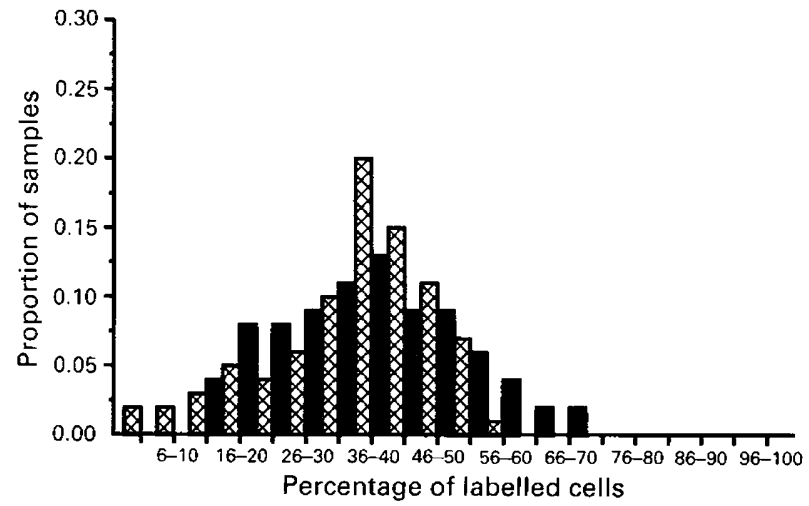

Fig. 6. Frequency distributions comparing the percentage of labelled (囚) granulosa cells with $(\boldsymbol{\square})$ the surface epithelium from chimaeric mouse ovaries. There were five progenitor cells for granulosa cells and two progenitor cells for surface epithelium and the standard errors of the differences between chimaeras were $4.6 \pm 0.2$ and $1.8 \pm 0.11$, respectively.

binomial statistics was 5 (Nesbitt, 1971; Stone, 1984). Despite the potential problem of cell selection in rapidly growing cell populations, this result is in agreement with that obtained by Telfer et al. (1988) who used different methods. Furthermore, the frequency distributions of labelled cumulus and mural granulosa cell subpopulations were indistinguishable, confirming that they have a common origin.

It is apparent, therefore, that the differentiation of progenitor granulosa cells in preantral follicles into distinctive phenotypes (Zoller and Weisz, 1978, 1979; Zoller and Enelow, 1983; Erickson et al., 1985) is not attributable to cell lineage, that is, there is no differential progenitor cell proliferation between the different follicular stages. The possibility that a gradient of morphogen(s) established between the theca and oocyte is responsible for differentiation warrants experimental attention. According to this hypothesis, cell destiny would be determined 
by positional cue(s) that have been demonstrated to be important in other developing organs (Izpisúa-Belmonte et al., 1992). Since the follicle wall is avascular, there will be gradients of $p \mathrm{O}_{2}$, hydrogen ions and metabolites across the granulosa layers (Gosden and Byatt-Smith, 1986), but other, more specific, products from the oocyte or theca cells might be involved. Alternatively, changes induced in cumulus or mural cells resting on the zona pellucida or basement membrane, respectively, might be transmitted by small molecules passing from cell to cell between communicating gap junctions (Anderson and Albertini, 1976; Gilula et al., 1978).

As successive layers of granulosa cells form preferentially by radial growth rather than by circumferential divisions, the implication is that the more peripheral cells would have to become either less densely packed or larger or broader as the cone elongates. Although it is clear that lateral growth must account for some of the increase in follicle diameter, this was not as pronounced as radial proliferation. It has been suggested that the cells resting on the basement membrane in late antral follicles are larger than those in the central region (Rauscher, 1965; Rao et al., 1991), but relevant morphometric data are not available for earlier stages of development. In addition, the presence of collagen in the basement membrane surrounding the follicle may contribute to cell spreading, reducing the number of cells around the follicular periphery and thus narrowing the base of the granulosa cell cone. Finally, the formation of columns is consistent with the suggestion that the membrana granulosa is at least partly pseudostratified in some species (Lipner and Cross, 1968).

The absence of a clear pattern of labelling in the corpora lutea contrasted with the findings in the follicle. This result is to be expected, as the follicle becomes invaded after ovulation by theca cells and blood vessels and the folding of the granulosa epithelium will further contribute to cell mixing (Corner, 1919; Alila and Hansel, 1984).

The theca interna can be distinguished from other types of cell on the basis of a phenotype resembling other steroidproducing cells and its location adjacent to the basement membrane. There were large patches of lateral clonal growth, which were quite distinct from the labelling percentages and patterns in subjacent granulosa cells. This finding suggests that the layer forms by the lateral spreading of a few precursor cells (two, according to binomial statistics) rather than by the recruitment and differentiation of many adjacent cells in the interstitium. Cells giving rise to the definitive theca interna may be present from the earliest stages of development. The frequency of labelling around the outside of follicles at all stages of preantral growth was frequently very different from that of the surrounding interstitial tissue. Moreover, the frequency distribution for these labelled cells around immature follicles was not significantly different from that of the theca interna around follicles that had reached the antral stage. In contrast, the labelling pattern among neighbouring theca externa cells resembled that of the interstitial tissue around the follicle. It was more diffuse with highly branched patches of interconnecting cells and the frequency distributions of interstitial tissue and theca externa resembled each other more than the theca interna.

Although these findings do not disprove the long-standing hypothesis that maturing follicles induce the differentiation of theca from stromal precursors (Hisaw, 1947; Dubreuil, 1948; Quattropani, 1973; Erickson et al., 1985), they are consistent with a view that theca interna (but probably not externa) cells are committed at a very early stage of follicle development, and, therefore, that the two types of theca cells have different origins. This is a different conclusion from that reached by Patek et al. (1991) in a study of XX-XY chimaeric ovaries, but our findings are consistent with the results of a study using tritiated thymidine autoradiography by Hirshfield (1991), who demonstrated the presence of labelled pretheca cells in unilaminar follicles against a background of relatively unlabelled interstitial cells. More tentatively, evidence was obtained that suggests that prospective theca interna cells may already be committed to this lineage from very early stages of follicle development.

Preferential adhesion of cells of the same genotype is always a consideration when analysing clonal patterning in chimaeras. However, the presence of different labelling patterns in the four cellular compartments of the same chimaeric ovary suggested that preferential adhesion was not dominating ovarian morphogenesis in this study, otherwise random patches would have been seen throughout. The differing labelling frequencies of granulosa, theca interna and theca externa-interstitial cells in the same ovaries strongly imply that each type of cell is derived from a separate lineage. However, there is some evidence to suggest that granulosa cells and surface epithelium are clonally related, as there was no significant difference between the frequency distribution of percentage of labelled cells between these two types of cell. The suggestion of a common, or related, clonal origin for these cells is supported by the observation that the two cell types arise, at least in part, from the coelomic epithelium during embryogenesis (Makabe and Motta, 1989; Wartenberg, 1989). Finally, the presence of both positive and negative hybridization signals within all the different cellular compartments of the ovary indicates that granulosa, theca interna, theca externa-interstitial cells and surface epithelium are oligoclonal in origin.

In summary, this study has shown that follicles are constructed by the non-random, radial proliferation of granulosa cell clones which form long, thin, unbranched columns across the follicle wall. This clonal pattern is in contrast to the extensive lateral coherent clonal growth exhibited by theca interna which encompasses the follicle. It is possible that granulosa cells and surface epithelium are closely related by clonal origin and that theca externa is very probably derived from interstitial tissue. Results from this study do not support the view that theca interna and theca externa-interstitial tissue have a common origin, and it is suggested that the former type of cell may exist in an undifferentiated state from the earliest stages of follicle development.

Further chimaeric studies during embryogenesis and early neonatal life could contribute to elucidating the origins and lineages of all these types of ovarian cell.

This work was supported by Wellcome Trust Grant 19292 (R. G. Gosden) and by a Wellcome Trust Prize Studentship (N. I. Boland). Thanks go to K. Grant and J. Verth for their technical assistance, and to $\mathrm{M}$. Keighren for determining the genotype of the chimaeric mice. Finally, the authors gratefully acknowledge J. West for his helpful comments on this manuscript. 


\section{References}

Alila HW and Hansel W (1984) Origin of different cell types in the bovine corpus luteum as characterized by specific monoclonal antibodies Biology of Reproduction 31 1015-1025

Anderson E and Albertini DF (1976) Gap junctions between the oocyte and companion follicle cells in the mammalian ovary Joumal of Cell Biology $\mathbf{7 1}$ 680-686

Byskov AG (1986) Differentiation of mammalian embryonic gonad Physiology Reviews 66 71-177

Corner GW (1919) On the origin of the corpus luteum of the sow from both granulosa and theca interna American Journal of Anatomy 26 117-183

Dubreuil G (1948) Sur l'éxistence d'une substance inductrice à action limiteé et locale pour la metaplasie thecale des cellules du stroma cortical ovarien Annals of Endocrinology 9 434-442

Erickson GF, Magoffin DA, Dyer CA and Hofeditz C (1985) The ovarian androgen-producing cells: a review of structure/function relationships Endocrinology Reviews 6 371-399

Gilula NB, Epstein ML and Beers WH (1978) Cell-to-cell communication and ovulation. A study of the cumulus-oocyte complex Journal of Cell Biology 78 58-75

Ginsberg M, Snow MHL and McLaren A (1990) Primordial germ cells in the mouse embryo during gastrulation Development 110 521-528

Gosden RG and Byatt-Smith JG (1986) Oxygen concentrations across the follicular epithelium: model, predictions and implications Human Reproduction 1 65-68

Gosden RG, Laing SC, Flurkey K and Finch CE (1983) Graafian follicle growth and replacement in anovulatory ovaries of ageing C57BL/6J mice Journal of Reproduction and Fertility $69453-462$

Hirshfield AN (1991) Theca cells may be present at the onset of follicular growth Biology of Reproduction 44 1157-1162

Hisaw FL (1947) Development of the Graafian follicle and ovulation Physiology Reviews 27 95-119

lzpisúa-Belmonte JC, Brown JM, Crawley A, Duboule D and Tickle C (1992) Hox-4 gene expression in mouse/chicken heterospecific grafts of signalling regions to limb buds reveals similarities in patterning mechanisms Development 115 553-560

Keighren M and West JD (1993) Analysis of cell ploidy in histological sections of mouse tissues by DNA-DNA in situ hybridization with digoxigenin labelled probes Histochemical Journal 25 30-44

Lipner H and Cross NL (1968) Morphology of the membrana granulosa of the ovarian follicle Endocrinology 82 638-641

Lo C (1986) Localization of low abundance DNA sequences in tissue sections by in situ hybridization Joumal of Cell Science 81 143-162
Makabe S and Motta PM (1989) Migration of human germ cells and their relationship with the developing ovary: ultrastructural aspects. In Developments in Ultrastructure of Reproduction pp 4I-54 Ed. PM Mott. Alan R Liss Inc., New York

Mintz B (1971) Methods in Mammalian Embryology Ed. JC Daniel. WH Freeman and Company, San Francisco

Nesbitt MN (1971) X chromosome inactivation mosaicism in the mouse Developmental Biology 26 252-263

Nicholson GL, Yanagimachi R and Yanagimachi H (1975) Ultrastructural localization of lectin-binding sites on the zona pellucidae and plasma membrane of mammalian eggs Journal of Cell Biology 66 263-274

Patek CE, Kerr JB, Gosden RG, Jones KW, Hardy K, Muggleton-Harris AL, Handyside AH, Whittingham DG and Hooper ML (1991) Sex chimaerism, fertility and sex determination in the mouse Development 113 311-325

Quattropani SL (1973) Morphogenesis of the ovarian interstitial tissue in the neonatal mouse Anatomical Records 177 569-584

Rao IM, Allsbrook WC, Jr, Conway BA, Martinez JE, Beck JR, Pantazis CG, Mills TM, Anderson E and Mahesh VB (1991) Flow cytometric analysis of granulosa cells from developing rat follicles Journal of Reproduction and Fertility 91 521-530

Rauscher H (1965) Die ovulation (morphologie) Archives Gynäkologic 202 $122-131$

Stone M (1984) Variance-covariance modelling with chromosome markers Journal of Theoretical Biology 107 275-286

Telfer E, Ansell JD, Taylor H and Gosden RG (1988) The number of clonal precursors of the follicular epithelium in the mouse ovary Journal of Reproduction and Fertility 84 105-110

Wartenberg H (1989) Ultrastructure of fetal ovary including oogenesis Ultrastructure of Human Gametes and Early Embryogenesis pp 61-68 Eds J Van Blerkhom and PM Motta. Kluwer Academic Publishers, Boston

Zoller LC and Enelow R (1983) A quantitative histochemical study of lactate dehydrogenase and succinate dehydrogenase activities in the membrana granulosa of the ovulatory follicle of the rat Histochemical Journal $\mathbf{1 5}$ 1055-1064

Zoller LC and Weisz J (1978) Identification of cytochrome P-450, and its distribution in the membrana granulosa of the preovulatory follicle, using quantitative cytochemistry Endocrinology 103 310-313

Zoller LC and Weisz J (1979) A quantitative cytochemical study of glucose6-phosphate dehydrogenase and $\Delta^{5}$-3 $\beta$-hydroxysteroid dehydrogenase activity in the membrana granulosa of the ovulable type of follicle in the rat Histochemistry 62 125-135 